\title{
OKSALE: Building a Culturally Responsive Virtual Library of Education Resources for a Tribal College
}

\author{
By Loriene Roy, \\ Graduate School of Library and Information Science \\ The University of Texas at Austin
}

\begin{abstract}
In spring 2001 students at the Graduate School of Library and Information Science at The University of Texas at Austin created a Virtual Library of education resources for pre-service teachers at Northwest Indian College (NWIC) in Lummi, Washington, one of thirty-two tribal colleges in the United States. The Virtual Library includes pathfinders on topics such as emergent literacy and the impact of technology on indigenous peoples. In addition, the Virtual Library includes links to related sources in Information Literacy and library instruction as well as handouts providing instruction on using applications such as PowerPoint Adobe Photoshop, and Flash.
\end{abstract}

\section{Introduction}

Nationwide, less than one percent $(18,000)$ of teachers are Native American (Koger, 2000). Most Native American children are taught by adults who are not culturally connected to a tribal community. This results in high turnover among staff at tribal schools and disconnection between tribal schools and the communities they serve.

Several initiatives are underway to increase the number of Native educators. Twenty-seven of the thirty-two tribal colleges award education certificates or degrees (Schubert, 2000). One program is Oksale, the Native Teacher Preparation Program at Northwest Indian College (NWIC) on the Lummi, Reservation, north of Bellingham, Washington. Oksale, which means teacher in the Lummi Coastal Salish language, began in 1997 through a grant from the W. K. Kellogg Foundation (Schubert, 2000; Northwest Indian College, n.d.). Oksale courses are offered in conjunction with Washington State University in Bellingham. Graduates of the program receive a Bachelor of Arts Degree in Elementary Education with K-8 certification (Schubert, 2000; Northwest Indian College, n.d.).

In late 2000 Portland (Oregon) State University's (PSU) Graduate Teacher Education Program received a $\$ 45,000$ extension to a 1999-2002 U. S. Department of Education Preparing Tomorrow's Teachers to Use Technology (PT3) grant to collaborate with NWIC (Lois Cohen, email to Portland State University PT3 Project, September 15, 2000). Faculty at NWIC requested that

\section{Oksale Virtual Library: Content}

Content for the Virtual Library evolved from class discussions, communication with Dr. Vivian Delgado who is the Oksale program director, input from the ACES team, and incorporation of scheduled assignments in Dr. Roy's spring 2001 classes. After the list of content ideas was generated, the Library Instruction class identified four main content areas: Educational Resources, Technology Tips, Library Resources, and Useful Links. The class consciously chose to use four divisions to reflect Native American cultural philosophies that honor four cardinal directions, four seasons, and four ages of human kind (infancy, childhood, adult hood, and elder age). This philosophy is also reflected in the use of a circle image on the home page.

Since the Virtual Library was designed at the request of the Oksale program, the Educational Resources section is the most important of the four main areas. The twelve students in Dr. Roy's Information Resources in the Social Sciences class created pathfinders based on topics mentioned in a selection of Oksale program syllabi such as Journal Writing and Media Literacy. The pathfinders each include an introduction to the pathfinder topic and a description of the search strategy the student followed, an annotated bibliography of fifteen to twenty-five resources, and a pathfinder or outline that provides instruction on how to locate information on the chosen topic.

In addition to these are links to sources of information on creating culturally responsive curricula for Native 


\section{Figure 1: Oxsale Virtual Library Home Page}

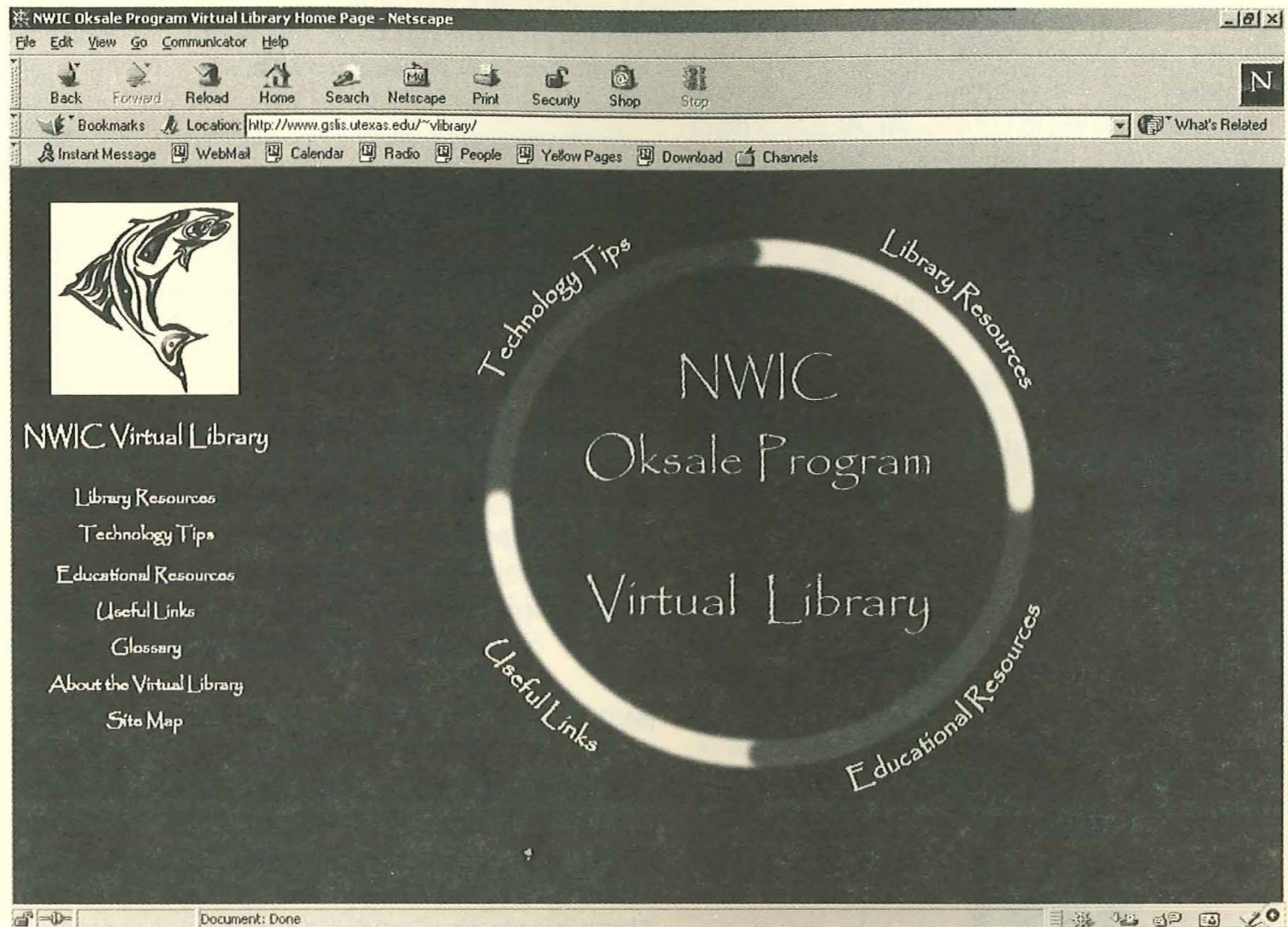

American students, fifty annotated links to sources on lesson plans,links to sites for children and parents, including homework help. Also, Education Resources includes information on Information Literacy organizations and models.Gregory Cajete and Carol Kuhlthau permitted the students to provide online versions of several writings (Cahete,1994; Kuhlthau,1994).

\section{Oksale Virtual Library: Design}

The GSLIS students were concerned that the graphics and design be respectful and reflective of Lummi culture. Dr. Vivian Delgado, Oksale Program Director, recommended that Library Instruction students consult Dr. Gregory Cajete's book, Look to the Mountain, for guidance on how to adapt the Virtual Library site to reflect indigenous models of learning (Cahete, 1994).

Valerie Valdez, one of the Library Instruction students, assumed the responsibility of suggesting graphics to the class. She conducted an Internet search of Lummi art, which provided suggestions of tribal colors (red, black, and white) and graphics, and designed original watercolor animals that became the basic imagery on the web site. GSLIS students selected the salmon to respect this valuable source of food for the Pacific Northwest peoples and its place as an esteemed spirit of the natural world. The eagle is found in the Lummi Nation seal. Students chose the frog as the Lummi people consider it as an auspicious being. Lastly, students decided on the raven in the format of a carved cedar pole.

Other design decisions are evident in the section of the Web site called About This Virtual Library. Library Instruction students felt that creating the Virtual Library was a journey like a river sometimes rambling, sometimes rushing and churning within its confines, thus the main imagery of this section is a river.

The river involves smooth travel as well as coursing through and among potential river hazards, illustrated by a series of linked boulders. River imagery was also appropriate since Lummi tribal land is associated with water, both sweet and salt. 


\section{Oksale Virtual Library: Communication and Decision-Making}

The Oksale Web site was constructed following a process that involved communal decision-making. As a service-learning project, the process also tried to provide students with opportunities to contact the ACES project community and to reflect on their work. Communication during the Web site construction included GSLIS students, ACES partners, Oksale students, NWIC information specialists (including Ms. Nancy Carroll, the Lummi Reservation Library System librarian), Lummi tribal members, researchers on information seeking behavior and Native American education, and those involved in the American Indian Higher Education Consortium (AIHEC) Virtual Library project at the University of Michigan and at Bay Mills Community College in Brimley, Michigan.

Figure 2: Eagle Graphic

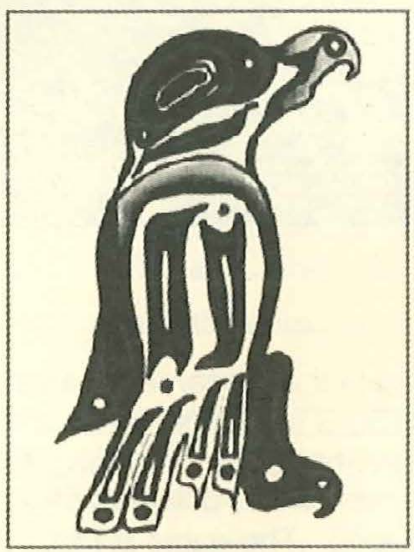

In addition to class discussion and deliberation, the students created several documents to help coordinate decision-making. One document was a sign-up list by which students selected the content areas and technology areas on which they would work. Each student selected a primary technology area for which they would provide advice to other students and one or more secondary technology areas.

Early in the process, Dr. Roy created several versions of a graphic illustration of the Web site, using Inspiration software. Relying on previous web development experience, Aimee Akerman, a GSLIS student, drafted statements reflecting site development standards, file structure and file submission guidelines, and a site map outline.Evaluation of the site involved sharing the URL with NWIC, the ACES team and others involved in indigenous library development. Students also placed a feedback form on the Web site and gathered responses when they demonstrated the work on-site at NWIC.
Work on the Oksale Program Virtual Library is ongoing as is the informal partnership begun with NWIC and ACES. It is the hope of the GSLIS students that the Virtual Library will continue to be a useful resource for Oksale program students and faculty. At least until final transfer of the Virtual Library is made to NWIC, the Virtual Library can be found at

http://www.gslis.utexas.edu/ vlibrary (Roy, 2001).

\section{References}

Cahete, G. (1994) Look to the mountain; An ecology of indigenous education. Skyland, NC: Kivaki Press.

Koger, C. (2000) Less than 1 percent of teachers are American Indians, but a $\$ 10$ million federal program hopes to add 1,000 more within five years.

Retrieved from http://www.inform.umd.edu/ EdRes/Topic/Diversity/Specific/Race/Specific/ Native_American_Resources/Announcements/ teachers.html

Kuhlthau, C. C. (1994).Students and the information search process: Zones of intervention for librarians. In Irene P.Godden, ( Ed.) . Advances in Librarianship 18, 57-72. New York: Academic Press.

Northwest Indian College. (n.d.) Native teacher preparation program. Bellingham, WA: Northwest Indian College.

Roy, L. (May 2001) NWIC Oksale Program Virtual Library. Retrieved from http://www.gslis.utexas.edu/ vlibrary.

Schubert, R. (2000). Native American program graduates first class of teachers. Retrieved from http://seattlepi.nwsource.com/ local/natv10.shtml

Figure 3: Frog Graphic

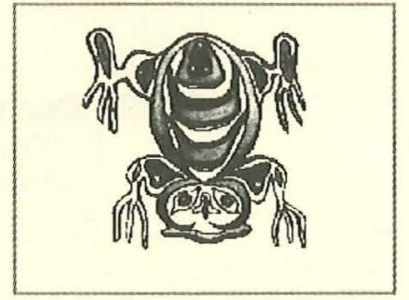

Dr. Loriene Roy is Associate Professor, Library and Information Studies, University of Texas, Austin. Her work has been recognized by the Tucker Foundation with a recent grant to continue an emerging site:

If I Can Read, I Can Do Anything. 